\title{
Epidemiologia das infecções por rotavírus no Brasil e os desafios para o seu controle
}

\author{
Rotavirus infection in Brazil: \\ epidemiology and challenges for control
}

Alexandre C. Linhares 1

\footnotetext{
1 Serviço deVirologia Geral, Instituto Evandro Chagas, Fundação Nacional de Saúde. Av. Almirante Barroso 492, Belém, PA 66090-000, Brasil. linhares@supridad.com.br
}

Abstract Worldwide, rotaviruses account for 600,000 to 870,000 deaths per year among infants and young children. In Brazil, rotaviruses were first seen in 1976 by scanning electron microscopy of stool samples from diarrheic infants in Belém, Pará. Hospi tal-based stu dies have shown that rotaviruses are associated with $12-42 \%$ of cases of acute diarrhea. In addition, community-based studies yiel ded an average of 0.25 rotavirus-related diarrheal epi sodes per child per year. G types 1 to 4 account for about two-thirds of circulating strains, but the (unusual) $\mathrm{P}[8], \mathrm{G} 5$ genotype has been claimed to cause over $10 \%$ of rotavi rus diarrheal episodes. It has been shown that over $70 \%$ of chil dren devel op rotavirus antibodies by theage of $4-5$ years. The tetravalent rhesus-human rotavirus vaccine (RRV-TV) conferred $35 \%$ protection according to a twoyear foll ow-up study in Belém, Pará, Brazil, but reached an efficacy of $60 \%$ during the first year of Iife. RRV-TV was also shown to be $75 \%$ protective against very severe gastroenteritis in northern Brazil. Vaccination with RRV-TV has been suspended recently in the United States because of the detection of intussusception as a side effect. Therefore, further vaccine trials in Brazil will probably involve rotavirus candi date vaccines other than RRV-TV.

Key words Rotavirus; Control; Epidemiology

Resumo Os rotavírus causam de 600.000 a 870.000 óbitos por ano entre crianças em todo o mundo. Esses vírus foram visualizados pela primeira vez no Brasil em 1976, a partir da microscopia el etrônica das fezes de crianças diarréi cas em Bel ém, Pará. Estudos conduzi dos em hospitais regi straram prevalência de diarréi a por rotavírus de $12 \%$ e 42\%. A par disso, investi gações Iongi tudinais assi nalaram taxa média de 0,25 epi sódi o de diarréia por criança/ano. Os tipos G1, G2, G3 e G4 representam cerca de 2/3 das amostras circulantes, porém, sustenta-se que o genótipo P[8], G5 associa-se a, no mínimo, 10\% das di arréi as. Estudos sobre a imunidade natural para rotavírus revelaram que $70 \%$ das crianças adqui rem anticorpos já aos 4-5 anos de idade. A vacina tetravalente, de origem sími o-humana (RRV-TV) conferiu proteção de 35\% após dois anos de estudo; contudo, o nível protetor alcançou $60 \%$ no primei ro ano de vida. A RRV-TV, no norte do Brasil, revel ou efi cácia de 75\% frente às di arréias graves. Há poucos meses interrompeu-se o uso dessa vacina nos EUA devido à ocorrência de intussuscepção como efei to colateral. É provável que futuros experimentos no Brasil contemplem outras "candi datas" a vacina contra rotavírus, que não a RRV-TV.

Palavras-chave Rotavírus; Controle; Epidemiologia 
Introdução

Os rotavírus representam a causa mais comum de diarréia grave na infância em todo o mundo. Nos países em desenvolvimento, particuIarmente, estima-se que as gastroenterites associadas a esses agentes virais determinem 600.000 a 870.000 mortes a cada ano, cifras que refletem 20 a $25 \%$ do total de óbitos por doença diarréica, bem como $6 \%$ da mortalidade global entre crianças com idades inferiores a cinco anos. Em cifras mais eloqüentes, morrem a cada dia 2.000 crianças com quadro diarréico causado por esses patógenos (de Zoysa \& Feachem, 1985; Institute of Medicine, 1986). O acesso amplo a uma vacina eficaz ora se constitui como única estratégia viável no tocante ao controle global das diarréias por rotavírus, de vez que são similares os indicadores de morbidade, se comparados os países desenvolvidos àqueles do Terceiro Mundo (Bresee et al., 1999). No que tange a essas últimas regiões, por conseguinte, práticas dirigidas à promoção do saneamento básico e das medidas de higiene se afiguram como de eficácia limitada.

As primeiras investigações sobre gastroenterites por rotavírus na América Latina remontam a meados da década de 70, poucos anos após a descoberta desse enteropatógeno por Bishop et al. (1973), ressaltando-se o caráter pioneiro dos estudos conduzidos à época no Brasil (Linhares et al, 1977; Linhares \& Bresee, submetido). Ao longo de duas décadas, múltiplos aspectos da infecção por esses vírus têm sido objeto de estudo em âmbito nacional, integrando um espectro que abrange desde os primeiros achados à microscopia eletrônica até a corrente caracterização molecular das cepas circulantes e os ensaios de campo com vacinas experimentais (Leite et al., 1996; Linhares, 1997; Santos \& Gouvea, 1997). Situadas entre esses marcos temporais, registrem-se as inúmeras investigações de caráter epidemiológico conduzidas no Brasil, revelando invariavelmente a magnitude que assumem as diarréias causadas pelos agentes virais em questão na infância. Conquanto sejam expressivos o volume e a multiplicidade de informações acerca das gastroenterites por rotavírus no país, as peculiaridades epidemiológicas vigentes impõem que se estabeleça uma extensa rede laboratorial com vistas à vigilância sistemática das amostras virais preval entes. Tal medida se justifica à luz das estratégias de vacinação em perspectiva (Linhares \& Bresee, submetido).

No presente relato, exploram-se os aspectos epidemiológicos das infecções por rotavírus no Brasil, cabendo ainda, nesse contexto, breves considerações relativas ao quadro clínico e à imunidade. A recente experiência com uma vacina contra rotavírus na região norte, e, como corolário, o advento de proposições visando ao controle das gastroenterites por esses patógenos, também merecem a devida análise.

\section{Aspectos epidemiológicos}

\section{Primeiros achados}

Remonta a 1976 o registro pioneiro quanto à detecção dos rotavírus no Brasil (Linhares et al., 1977), portanto, à época em que apenas emergiam as primeiras evidências consubstanciando a relevância epidemiológica universal desses agentes como enteropatógenos (Bishop et al., 1973; Flewett $\&$ Woode, 1978; Candeias et al., 1989). Esses resultados advieram de estudo-piloto conduzido em Belém, Pará, envolvendo 25 crianças sob atendimento ambulatorial ou hospitalizadas, com quadro diarréico agudo. O recurso da microscopia eletrônica e, subseqüentemente, do procedimento imunoenzimático (ELISA), propiciou a detecção dos rotavírus em espécimes fecais de quatro (16\%) pacientes (Linhares et al., 1977; Linhares et al., 1982). Tais observações originais representaram o marco inicial de inúmeros outros estudos no país, a maioria dirigida ao impacto determinado pela doença moderada ou grave por rotavírus, qual seja, a que se traduz em consultas médicas e internação hospitalar (Pereira et al., 1993; Linhares, 1997; Oliveira \& Linhares, 1999). Em menor escala, sucederam-se investigações no seio da comunidade, a título de configurar a história natural das infecções, via de regra prospectivas e atinentes a condições clínicas de gravidade menos expressiva.

\section{Infecções por rotavírus no âmbito} de ambulatórios e hospitais

Vários foram os estudos até então empreendidos em território brasileiro, abrangendo as diferentes regiões do país, com base nos quais se determinaram múltiplas taxas relativas à prevalência das diarréias por rotavírus entre crianças com idades inferiores a seis anos (Tabela 1). O contingente sob investigação era representado em sua quase totalidade por demanda ambulatorial ou hospitalar, depreendendo-se, por conseguinte, que os indicadores de morbidade daí advindos retratam as situações clínicas efetivamente mais graves. Em termos gerais, a freqüência de diarréias associadas a rotavírus variou de $12 \%$ a $42 \%$. Se consideradas as médias 
dos índices de positividade por região, ressalte-se o Norte com 36,5\% (Linhares et al., 1983b; Linhares et al., 1993), registrando-se ainda taxas de $25 \%$, $24 \%$, $22 \%$ e $42 \%$, para Nordeste (Houly et al., 1986; Stewien et al., 1991), Centro-oeste (Cardoso et al., 1989; Teixeira et al., 1991; Cardoso et al., 1992), Sudeste (Rácz et al., 1988; Candeias et al., 1989; Gatti et al., 1989; Gomes et al., 1991; Mangia et al., 1993; Stewien et al., 1993) e Sul (Coiro et al., 1985), respectivamente. Atribua-se a tal comparação, entretanto, o caráter de estimativa, face à nítida diversidade logística, metodológica e temporal que permeia os estudos em questão.

Admite-se que a representatividade mais expressiva quanto à freqüência da doença causada pelos rotavírus no Brasil resida nos resultados oriundos de investigação abrangente, envolvendo 14 estados, conduzida há aproximadamente uma década (Pereira et al., 1993). O inquérito nacional compreendeu a utilização de um único procedimento diagnóstico - o que enseja comparabilidade mais efetiva -, reuniu aproximadamente 11.000 espécimes clínicos e resultou em prevalências que variaram de $13 \%$ a $20 \%$. Depreende-se que tal faixa de positividade, inferior àquela delimitada nos estudos independentes antes referidos, decorre da expressiva parcela representada pelos pacientes sob consulta ambulatorial, em nítido contraste com o contingente dos internados nas enfermarias pediátricas.

De um modo geral, os dados disponíveis indicam que pelo menos $2 / 3$ dos processos diarréicos por rotavírus se situam na faixa etária de 6 a 24 meses, embora mereça registro a relativa freqüência das infecções sintomáticas durante o primeiro semestre de vida. (Linhares et al., 1983b; Teixeira et al., 1991; Cardoso et al., 1992; Linhares, 1997).

A distribuição sazonal das gastroenterites por rotavírus no Brasil assume duas configurações bem distintas, em consonância com os padrões registrados nas regiões temperadas e tropicais do planeta (Cook et al., 1990; Pereira et al., 1993; Linhares, 1997). Com efeito, centrooeste e sudeste/ sul brasileiros exibem marcante perfil sazonal, observando-se maior incidência nos meses mais secos (maio a setembro) (Gomes et al., 1991; Teixeira et al., 1991; Cardoso et al., 1992; Stewien et al., 1993); em contrapartida, nos estados do Norte/ Nordeste, tal sazonalidade não se revel ou tão marcante (Linhares et al., 1983b; Stewien et al., 1991) (Figura 1).

À luz de dados oficiais (DATASUS, 1997), ocorreram 254.949 internações por doença infecciosa intestinal ao longo de 1997, envolvendo crianças em seu primeiro ano de vida. Admitindo-se que $34 \%$ dessas situações se associam
Tabela 1

Prevalência de gastroenterites agudas associadas a rotavírus entre crianças com idades inferiores a cinco anos, hospitalizadas ou atendidas em ambulatório, de acordo com regiões e estados do Brasil.

\begin{tabular}{|c|c|c|}
\hline Regiões e estados & $\begin{array}{l}\% \text { de positividade } \\
\text { para rotavírus }\end{array}$ & $\begin{array}{l}\text { Referências } \\
\text { bibliográficas }\end{array}$ \\
\hline \multicolumn{3}{|l|}{ Norte } \\
\hline \multirow[t]{2}{*}{ Pará } & 33,0 & Linhares et al., 1983 \\
\hline & 40,0 & Linhares et al., 1993 \\
\hline \multicolumn{3}{|l|}{ Nordeste } \\
\hline Alagoas & 13,3 & Houly et al., 1986 \\
\hline Maranhão & 25,0 & Stewien et al., 1991 \\
\hline \multicolumn{3}{|l|}{ Centro-oeste } \\
\hline \multirow[t]{2}{*}{ Goiás } & 22,7 & Cardoso et al., 1989 \\
\hline & 29,2 & Cardoso et al., 1992 \\
\hline Distrito Federal & 20,3 & Teixeira et al., 1991 \\
\hline \multicolumn{3}{|l|}{ Sudeste } \\
\hline Rio de J aneiro & 11,6 & Mangia et al., 1993 \\
\hline \multirow[t]{5}{*}{ São Paulo } & 28,9 & Candeias et al., 1989 \\
\hline & 16,0 & Gatti et al., 1989 \\
\hline & 14,0 & Gomes et al., 1991 \\
\hline & 28,9 & Rácz et al., 1988 \\
\hline & 19,0 & Stewien et al., 1993 \\
\hline \multicolumn{3}{|l|}{ Sul } \\
\hline Rio Grande do Sul & 42,0 & Coiro et al., 1985 \\
\hline
\end{tabular}

aos rotavírus (Linhares et al., 1983b), é plausível estimar-se, em bases conservadoras, o registro de aproximadamente 88.000 hospitalizações no país, na citada faixa etária. No tocante à mortalidade, a mesma fonte revela a ocorrência, naquele ano e mesma faixa etária, de 3.399 óbitos por diarréia de origem infecciosa presumível. Admitindo a associação de $40 \%$ deles aos citados agentes virais, bem como que as cifras oficiais - subestimadas - refletem $80 \%$ da dimensão real do agravo, resulta o total de mortes em aproximadamente 1.700 .

As infecções por rotavírus de origem nosocomial ainda representam um aspecto pouco explorado no contexto dos estudos epidemiológicos nacionais. A mais extensa investigação nesse particular se desenvolveu no norte do país, abrangendo 237 crianças admitidas em um hospital público de 1992 a 1994 (Gusmão et al., 1995; Gusmão et al., 1999). Concluiu-se que aproximadamente $1 / 3$ das gastroenterites agudas desenvolvidas no curso da internação se re- 
Figura 1

Distribuição temporal das freqüências de positividade para rotavírus, entre crianças portadoras de gastroenterite aguda, em três estados do Brasil. Adaptado de Pereira et al. (1993).
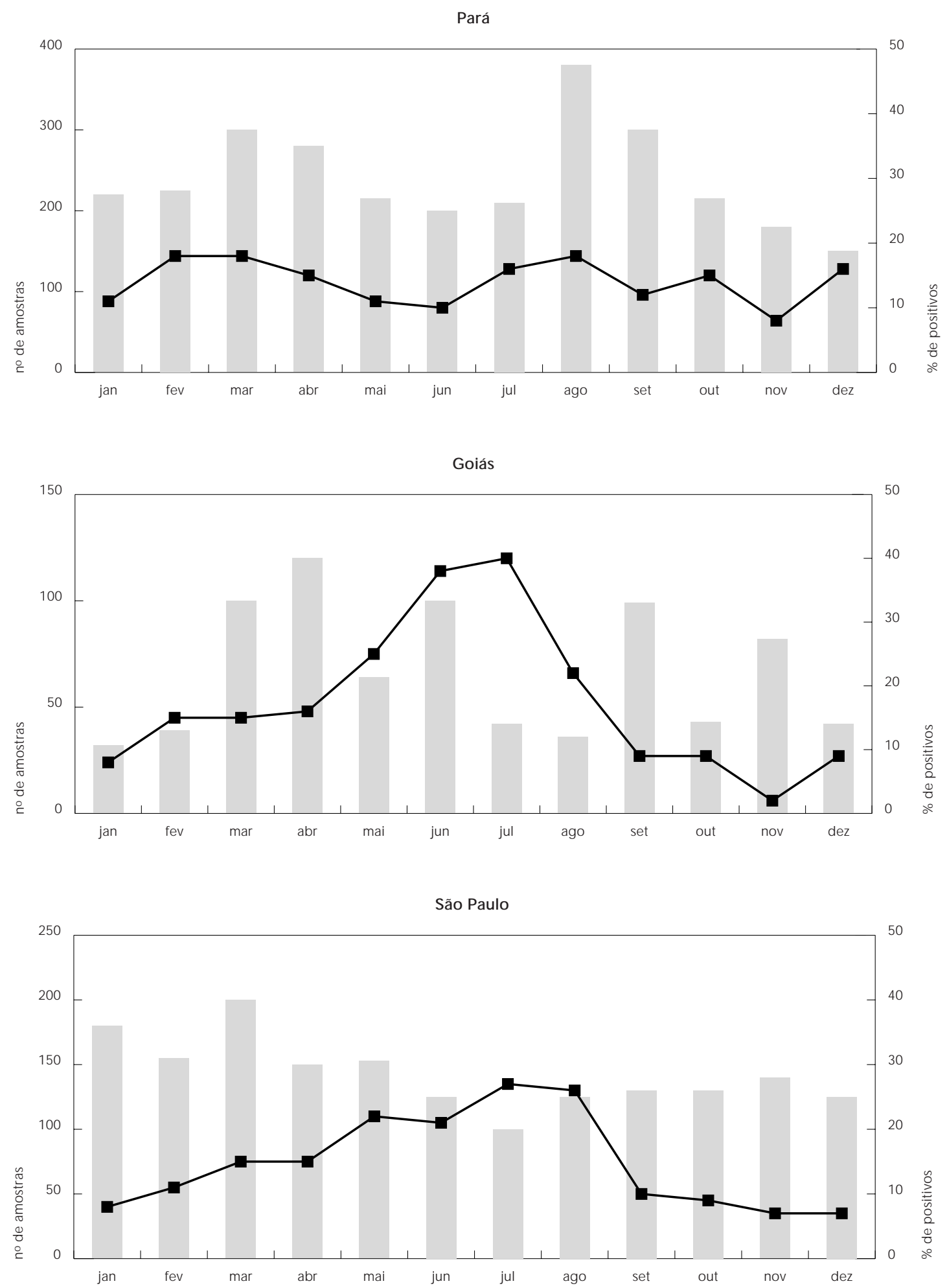
laciona aos rotavírus, denotando claramente a expressiva transmissibilidade desses agentes virais no ambiente hospitalar. Dignos de nota, ainda, nessa investigação, foram os achados obti dos em bases antigênicas e genômicas - indicativos de que as cepas virais circulantes nas enfermarias pediátricas refletem basicamente aquelas detectadas no meio externo ao hospital. Não obstante sobremaneira restritos no Brasil, estudos dirigidos a neonatos hospitalizados revelam aspectos epidemiológicos singulares das infecções por rotavírus, em nítido contraste com as características antes descritas. Com efeito, recente pesquisa conduzida em Belém, Pará, envolvendo mais de 400 recémnascidos com idades inferiores a um mês, indicou que pelo menos $80 \%$ desse contingente desenvolveram infecção assintomática (Linhares et al., s/d). Acresçam-se a esses achados as características genotípicas peculiares às amostras de rotavírus detectadas, divergindo das inerentes às que circulam nas áreas hospitalares reservadas aos pacientes pediátricos e mesmo na comunidade externa.

\section{Investigações prospectivas no âmbito} comunitário urbano

Os estudos longitudinais caracterizados pela vigilância ativa das infecções por rotavírus no seio da comunidade ocorreram em número relativamente reduzido ao longo das duas décadas em tela. Face à sua própria configuração metodológica (visitas domiciliares regulares a um mesmo grupo de crianças), tais investigações ensejaram a detecção de episódios diarréicos em geral leves ou moderados. Paralelamente, o caráter prospectivo desses procedimentos evidenciou a ocorrência de reinfecções, particularidade não explorada no contexto hospitalar ou ambulatorial.

Múltiplos aspectos concernentes à história natural das infecções por rotavírus no Brasil se elucidaram calcados em estudo conduzido na região norte, de 1982 a 1986, envolvendo cerca de 80 crianças acompanhadas quinzenalmente do nascimento aos três anos de idade (Linhares et al., 1989a). Observou-se que ocorrem, em média, 2,5 episódios diarréicos agudos por criança/ ano, dos quais $10 \%(0,25)$ se associam aos rotavírus; na metade das situações, cabe ressaltar, esses agentes representaram o único patógeno detectado. Destacou-se no conjunto desses achados o fato de as infecções inaparentes por tais vírus prevalecerem sobre as sintomáticas, entre crianças com idades inferiores a cinco meses. Tal condição se contrapôs ao registrado em grupos etários superiores.
No curso de investigação prospectiva mais recente (1990 a 1992), conduzida na mesma área (Linhares et al., 1994), registrou-se taxa anual de 0,2 caso de gastroenterite relacionada a rotavírus por indivíduo, similar à estabelecida antes, 0,25 (Linhares et al., 1989a). Estudos Iongitudinais desenvolvidos no nordeste revelaram índice pelo menos quatro vezes mais elevado, 1,33, a considerar-se o grupo etário de 6 a 11 meses (Guerrant et al., 1983).

A vigilância intensiva dos episódios diarréicos a que se procedeu no curso de recente investigação em Belém, Pará (Linhares et al., 1994; Linhares et al., 1996), ofereceu nítidos indicadores quanto à sazonalidade das infecções por rotavírus, ainda que sem o caráter marcante assinalado naquelas regiões de clima temperado do país (Pereira et al., 1993). Com efeito, na região norte, o período de julho a setembro exibe mais expressiva incidência das diarréias infantis por rotavírus, correspondendo aos meses em que se registra menor precipitação pluviométrica.

A detecção de reinfecções por rotavírus também representou achado relevante no curso dos estudos prospectivos. Em geral, à infecção envolvendo o sorotipo 1 sucedia-se outra pelo 2, nos primeiro e segundo anos de vida, respectivamente (Linhares et al., 1988a; Oliveira et al., 1994; Linhares, 1997).

\section{Surtos de gastroenterite aguda} em contingentes populacionais urbanos

São raros os relatos concernentes a surtos de gastroenterite por rotavírus no Brasil, na maioria das vezes circunscritos a áreas que reúnem aglomeração humana como escolas, creches, enfermarias hospitalares e mesmo o seio familiar. Nos primeiros meses de 1980, por exemplo, registrou-se extenso surto de diarréia em instituição de ensino privada do Rio de Janeiro, associado a rotavírus e Shigella sonnei (Sutmoller et al., 1982). Nesse estudo, sustenta-se que cerca de $75 \%$ dos estudantes e professores foram acometidos. Ainda naquele estado, investigações mais recentes assinalam a ocorrência de epidemia em uma creche, causada por rotavírus do tipo G1, atingindo $60 \%$ das crianças com idades inferiores a dois anos. Aliás, nenhum outro enteropatógeno que não os agentes virais em questão foi detectado ao exame dos espécimes clínicos de pacientes diarréicos (de Castro et al., 1994). Convém assinalar, nesse contexto, que elucidativa análise conduzida por Blake et al. (1993), em São Paulo, estabeleceu expressiva correlação entre o potencial de risco quanto ao desenvolvimento da diarréia por rotavírus e o acesso das crianças a creches. 
Assumiu características epidemiológicas singulares, por outro lado, recente epidemia de gastroenterite grave causada por rotavírus $\mathrm{G} 2$ em Mirassol, localidade situada no sudeste de São Paulo (Timenetsky et al., 1996). Com efeito, o registro de episódios diarréicos entre adultos, assim como as evidências da veiculação hídrica do agente viral, denotam os aspectos incomuns dessa ocorrência epidêmica.

Pelo menos dois estudos no país oferecem dados quanto à eclosão de surtos familiares, via de regra caracterizados por padrões bem definidos (Silva et al., 1984). Em geral o processo se estabelece a partir de quadro diarréico agudo envolvendo uma criança, as infecções subclínicas ou assintomáticas entre adultos são comuns e revela-se a circulação de uma única cepa viral.

Durante recente estudo em Belém, Pará, envolvendo cerca de quatrocentos recém-nascidos, demonstrou-se nitidamente a importância do ambiente hospitalar como determinante da rápida propagação dos rotavírus (Linhares et al., dados não publicados). Não obstante os dois anos (1996 a 1998) ao longo dos quais decorreu a investigação, as infecções (expressiva parcela assintomática) se situaram em período limitado, configurando-se a ocorrência de verdadeiro surto no âmbito nosocomial .

Sorotipos, genótipos e eletroferotipos de rotavírus no Brasil: variação temporal e peculiaridades

Em termos gerais, sabe-se que os quatro sorotipos reconhecidos como de importância epidemiológica universal [G (de glicoproteína)], G2, G3 e G4] ocorrem no Brasil, mesmo que recentes achados indiquem a circulação de cepas virais com características antigênicas incomuns (Kapikian \& Chanock, 1996; Linhares, 1997; Gouvea \& Santos, 1999).

As primeiras informações pertinentes à multiplicidade antigênica dos rotavírus detectados em casos de gastroenterite infantil resultaram de estudo longitudinal na comunidade, conduzi do no norte do país de 1983 a 1985 ( Linhares et al., 1988b; Linhares et al., 1989a). Os tipos $\mathrm{G} 1$ e G2 prevaleceram, concorrendo com $50 \%$ e $30 \%$ das amostras, respectivamente. No curso de investigação ulterior (1988), emergiu o G3 como único sorotipo circulante entre pacientes pediátricos (Linhares et al., 1993). Aproximadamente à mesma época, essa variedade antigênica também predominava entre crianças portadoras de gastroenterite aguda em São Luís, Maranhão, representando $41 \%$ do total das amostras circulantes (Stewien et al., 1994). Já no início da década de 90, os testes de cam- po com uma candidata a vacina contra rotavírus ensejaram nova determinação dos sorotipos prevalentes, destacando-se freqüências de $65 \%, 30 \%, 1,2 \%, 4,6 \%$ e $1,2 \%$ para os tipos $\mathrm{G} 1$, G2, G3, G4 e G9, respectivamente (Linhares et al., 1996). Subseqüentemente (1992 a 1994), em Belém, novo procedimento de vigilância das diarréias agudas no contexto nosocomial pediátrico revelou nítida inversão dos índices de positividade, então predominando amplamente (80\%) o G2 (Gusmão et al., 1995; Gusmão et al., 1999). Esse mesmo tipo também predominou ( $>90 \%$ ) quando se examinaram neonatos internados em um hospital público de Belém ao longo do triênio compreendido entre 1996 e 1998 (Linhares et al., dados não publicados). Dados mais recentes (1998 até janeiro de 2000), por outro lado, já denotam uma tendência à predominância do G1 (42\%) sobre o G2 (35\%), se considerados os episódios diarréicos mais graves, determinantes de internação hospitalar (Y. B. Gabbay, comunicação pessoal). Se o conjunto das informações concernentes à região norte do país é analisado à luz de uma perspectiva temporal, denota-se nítida flutuação das freqüências relativas dos sorotipos predominantes, com destaque para Gl e, secundariamente, G2 (Figura 2). Aliás tal característica epidemiológica é consentânea com o que se observa em escala universal (Beards et al., 1989). A título de consubstanciar tal asserção, assinalem-se os resultados de amplo estudo procedido por Pereira et al. (1993) no Brasil, durante uma década (1981 a 1990), alcançando índices de $42 \%$, $24 \%$, $16 \%$ e $18 \%$ para os tipos G1, G2, G3 e G4, respectivamente.

$\mathrm{O}$ advento de técnicas da biologia molecular propiciou a ampliação dos estudos epidemiológicos no país. Com efeito, tais recursos viabilizaram a determinação dos genótipos $\mathrm{G}$ e $P$, estes últimos, estabelecidos com base na diversi dade antigênica inerente à proteína de superfície viral VP4, sensível à protease. Estudos pioneiros nesse contexto se desenvolveram em São Paulo, abrangendo espécimes fecais de crianças diarréicas menores de quatro anos, entre 1986 e 1992 (Timenetsky et al., 1994). Nessa investigação, o genótipo G3 emergiu como predominante ( $22 \%$ das amostras analisadas), sucedido em escala decrescente de freqüência pelos tipos G1 (17\%), G2 (6\%) e G4 (5\%); registre-se ainda a expressiva proporção de cepas não tipadas, bem como das misturas complexas envolvendo especificidades genotípicas $\mathrm{G}$ e $\mathrm{P}$ não usuais. A predominância do sorotipo P1, correspondente ao genótipo P[8] (21\%), também foi notória, em nítida associação com as especificidades genômicas G1, G3 e G4. 


\section{Figura 2}

Distribuição dos tipos G de rotavírus em Belém, Pará, com base em estudos desenvolvidos de 1982 a 1998. Adaptado de: Linhares et al. (1988b), [1982-1986]; Linhares et al. (1993), [1988]; Linhares et al. (1996), [1990-1992]; Gusmão et al. (1999), [1992-1994]; Linhares et al. (dados não publicados), [1996-1997]; e Gabbay (comunicação pessoal), [1998].

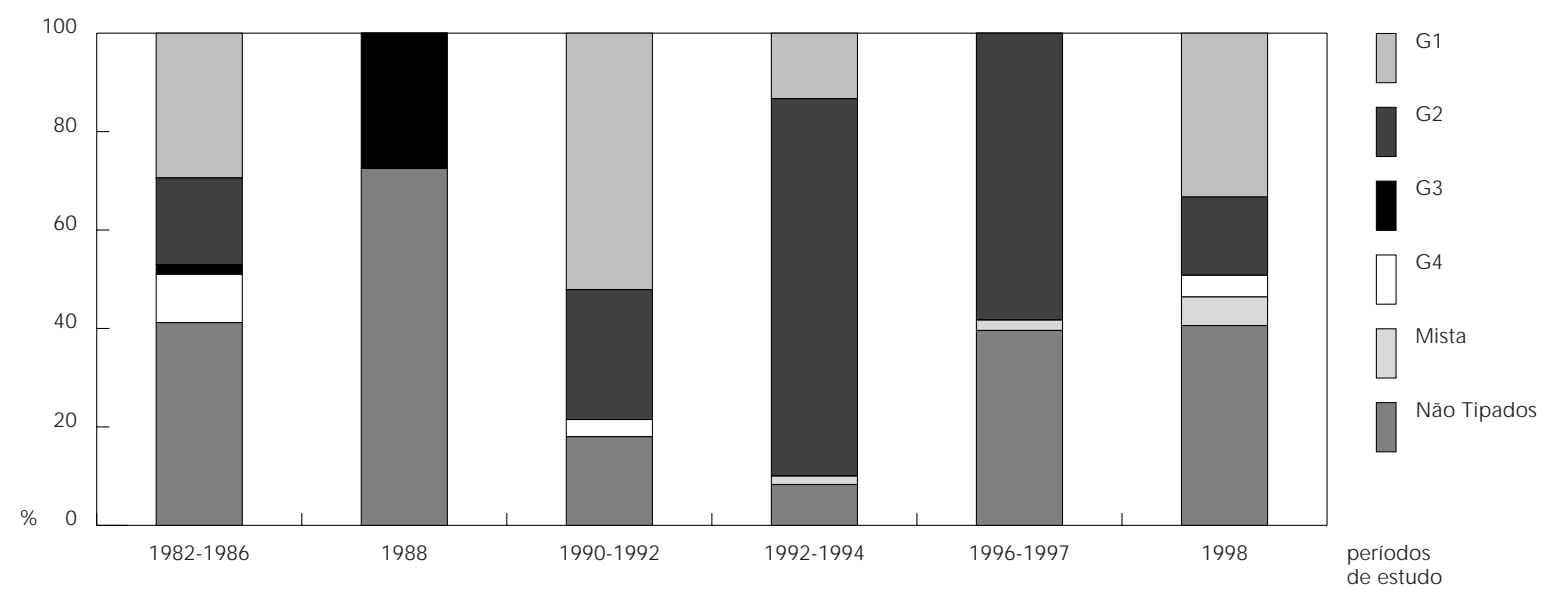

A mais extensa investigação conduzida no Brasil, com vistas à caracterização genotípica dos rotavírus, abrangeu nove estados e o Distrito Federal, incidindo sobre crianças diarréicas com idades inferiores a cinco anos (Leite et al., 1996). As amostras predominantes se reveIaram essencialmente as mesmas registradas em todo o mundo, expressas como segue com base na dualidade genotípica inerente às proteínas VP4 e VP7: P[8], G1, 43\%; P[4], G2, 12\%; P[8], G3, 6\%; e P[8], G4, 6\%. De particular importância, entretanto, revestiram-se os achados revelando a emergência do genótipo P[8], G5 em $12 \%$ das situações investigadas, o que suscita reservas quanto à possível eficácia da vacina tetravalente (G1, G2, G3 e G4) correntemente disponível (Bresee et al., 1999). A par disso, é digna de nota a expressiva parcela, $21 \%$, relativa às infecções mistas (diferentes genótipos detectados no mesmo espécime fecal), condição que favorece as reestruturações genéticas in vivo, e, conseqüentemente, a emergência de cepas com características atípicas. [Tal condição, vale ressaltar, já se registrou no norte do Brasil, onde permutas gênicas envolvendo os sorotipos 1 e 2 foram observadas (Mascarenhas et al., 1989) ]. Cabe registrar que a relevância epidemiológica inerente à detecção do G5 já se configurara antes, em caráter pioneiro, a partir das observações de Gouvea et al. (1994) em São Paulo, ao examinarem 38 casos de diarréia infantil. Consubstanciando essa notória singularidade antigênica e genotípica, assinalem-se recentes observações de Santos et al. (1998), no Rio de Janeiro, associando a ocorrência dos tipos G5, G8 e G10 a 40\% dos quadros diarréicos agudos envolvendo crianças com idades inferiores a cinco anos. Reservou particular interesse nesse contexto a caracterização, em bases moleculares, de amostra viral oriunda de criança diarréica cuja dualidade antigênica se expressava em termos dos tipos G5 e G11 (Timenetsky et al., 1997). Este último, cumpre assinalar, reconhecido até então como um agente patogênico exclusivo de suínos.

O recente emprego da RT-PCR ("reação em cadeia da polimerase" com o uso de transcrição reversa), também propiciou o reexame de amostras virais circulantes em diferentes períodos na região norte do país, antes caracterizadas no que tange à sua especificidade antigênica. Em Belém, por exemplo, observou-se que o genótipo P[8], G1 predominou amplamente à época em que se desenvolveu estudo prospectivo no âmbito comunitário (1982 a 1986), corroborando achados pregressos concernentes aos sorotipos predominantes (Linhares et al., 1988b; Mascarenhas et al., 1998). Estudo mais recente (1992 a 1994) no contexto hospitalar, por sua vez, registrou expressiva ocorrência do tipo P[4] - correlato ao G2 -, consubstanciando resultados estabelecidos anteriormente em bases antigênicas (Gusmão et al., 1995; Gusmão et al., 1999; Mascarenhas et al., 1999). Note-se, 
pois, a flutuação temporal dos tipos $\mathrm{P}$, definidos pela proteína VP4, à semelhança do que se observa em relação aos sorotipos $\mathrm{G}$, estes, atinentes à VP7.

Revestem-se de particular singularidade no panorama epidemiológico nacional, recentes observações indicando a elevada incidência de infecção assintomática por rotavírus caracterizados como P[6], G2, entre neonatos hospitalizados em Belém (Linhares et al., s/d).

A par dos múltiplos sorotipos e genótipos antes configurados, são vários os estudos no Brasil concernentes à diversidade dos el etroferotipos de rotavírus: padrões obtidos à eletroforese (polyacrylamide gel el ectrophoresis, PAGE) dos 11 genes integrantes do genoma viral. Sinteticamente, a maioria das investigações ressalta a predominância dos perfis “Iongos" (70\%, aproximadamente), em geral compatíveis com os sorotipos G1, G3 e G4. Não obstante em menor freqüência, aqueles designados de "curtos" (característicos do tipo G2) denotam configurações mais heterogêneas que os primeiros (Pereira et al., 1983a; Houly et al., 1986; Mascarenhas et al., 1988). A criteriosa análise das posições relativas desses 11 segmentos enseja, eventualmente, a detecção de "recombinações" (ou permutas) gênicas que originam padrões com características atípicas, como já assinalado na Amazônia (Gusmão et al., 1994; Mascarenhas et al., 1997).

O corrência de infecções

por rotavírus do grupo $\mathrm{C}$

Sustenta-se que os rotavírus do grupo C são patógenos primários de suínos, embora seja nítido o seu papel na gênese das gastroenterites humanas (Bridger et al., 1986). Não raro tais agentes se têm associado a surtos de diarréia em situações que ensejam a formação de agrupamentos humanos como, por exemplo, escolas e mesmo o seio familiar (Matsumoto et al., 1989; Maunula et al., 1992).

No Brasil, os dados pioneiros nesse contexto cabem a Pereira et al. (1983b), que descreveram a infecção por rotavírus do grupo $\mathrm{C}$ em criança portadora de quadro diarréico agudo na cidade do Rio de Janeiro. Estudos subseqüentes levados a efeito nas regiões norte, centro-oeste e sudeste bem denotaram a amplitude quanto à ocorrência desse patógeno no Brasil. Na região amazônica, o emprego da microscopia eletrônica e eletroforese do RNA viral em gel de poliacrilamida - ou PAGE - permitiu a detecção desses enteropatógenos em casos esporádicos de gastroenterite infantil, no curso dos anos 80 (Gabbay et al., 1989). A especifici- dade desses achados se corroborou ulteriormente com base em técnicas da biologia molecular, como a RT-PCR (Cooke et al., 1992). Ainda no norte do país, Gabbay et al. (no prelo) investigaram surto de gastroenterite ocorrido em creches que al bergavam crianças com idades inferiores a cinco anos, assinalando-se positividade para rotavírus do grupo C em quase $40 \%$ dos casos sob exame.

No Distrito Federal, centro-oeste brasileiro, Teixeira et al. (1998) caracterizaram rotavírus do grupo $\mathrm{C}$ em amostras fecais de crianças diarréicas e paciente imunodeprimido, ao longo de 1994, valendo-se do emprego do PAGE e RT-PCR.

Registre-se como peculiaridade epidemiológica a extensa ocorrência de infecções por rotavírus pertencentes ao grupo em questão entre adultos e crianças habitantes de Valentim, pequena cidade no norte de São Paulo, em 1993 (Souza et al., 1998). Em tal surto, ocorrido no bimestre julho-agosto, o uso de ELISA e outros procedimentos diagnósticos ensejou a detecção desses agentes em $70 \%$ dos pacientes diarréicos.

Estudos quanto à dinâmica da aquisição de anticorpos para rotavírus do grupo $\mathrm{C}$, recentemente conduzidos em São Paulo, indicaram que a infecção não é comum entre crianças com idades inferiores a cinco anos (Cox et al., 1998). Com a progressão etária, registrou-se aumento gradual nos índices de positividade - portanto, de supostas primoinfecções -, alcançando-se prevalência situada em $40 \%$ na idade adulta.

Infecções por rotavírus em comunidades indígenas: padrões epidemiológicos atípicos

Conquanto raros em âmbito nacional, os estudos concernentes às infecções por rotavírus em contingentes populacionais isolados revelam características epidemiológicas sobremaneira distintas daquelas que prevalecem na área urbana (Linhares, 1992; Linhares et al., 1992). Os primeiros relatos associando os rotavírus a quadros de gastroenterite aguda entre silvícolas no Brasil datam da década de 70. Com efeito, em 1977 registrou-se extenso surto de diarréia envolvendo os índios da aldeia Tiriyó (224 indivíduos), situada no norte do Pará, próxima ao Suriname (Linhares et al., 1981). A ocorrência epidêmica progrediu em intervalo de tempo relativamente curto, julho a agosto, envolvendo cerca de $90 \%$ da população sob risco, entre crianças e adultos; o segmento etário mais atingido, vale ressaltar, foi o representado por indivíduos com idades inferiores a cinco anos. A utilização, à época, da contra-imuno- 
eletroosmoforese ensejou a detecção de anticorpos para rotavírus em soros coletados antes e após a epidemia, registrando-se conversões (aumento de quatro vezes ou mais nos títulos) em pelo menos 3/4 da comunidade sob exame. Análises complementares baseadas nos procedimentos de imunofluorescência apontaram para o sorotipo G1 como agente etiológico. Aliás, a quase totalidade da população se caracterizava como absolutamente suscetível a esse tipo viral, face à ausência de anticorpos específicos em amostras de soro obtidas antes do surto. A gravidade com que se apresentaram os quadros clínicos, refletida por inúmeros casos de desidratação e um óbito, revelou-se particularmente notória entre as crianças.

Pelo menos dois aspectos conferem singularidade à situação acima descrita. Em primeiro lugar, o acometimento de adultos e crianças indistintamente; em segundo, o caráter explosivo do surto em questão, o que sustenta a hipótese de propagação via hídrica dos rotavírus. Há evidências epidemiológicas indicando que a introdução dos rotavírus na comunidade ocorreu a partir do retorno de um índio adulto (então diarréico) à referida aldeia, após concluir tratamento para doença respiratória a que se submeteu em Belém.

Com o intuito de dimensionar mais precisamente a extensão com que as populações indígenas na Amazônia se infectam por rotavírus, procedeu-se a amplo estudo de natureza soroepidemiológica, abrangendo 13 diferentes tribos da região (Linhares et al., 1986b). Os índices de positividade variaram de 18\% (Parakanã Novo) a 90\% (Kubenkrankégn), sugerindo níveis de exposição aos rotavírus amplamente variáveis; a primeira comunidade, cabendo assinalar, sob risco de epidemias com amplitude similar à que eclodiu entre os Tiriyó. Em algumas das tribos estudadas (Mayongóng, por exemplo, no território venezuelano), os níveis de prevalência aumentavam gradativamente com a idade, sugerindo a persistência dos rotavírus nesses agrupamentos humanos isolados da região amazônica. A par disso, a quase sistemática obtenção de resultados positivos em crianças de baixa idade reflete o potencial endêmico das infecções por rotavírus nesses núcleos populacionais.

São pertinentes no contexto sob exame, ainda, as observações de Santos et al. (1991) que identificaram expressivas taxas de positividade quanto à presença de anticorpos para rotavírus entre os Suruí (68\%) e Karitiána (77\%), em Rondônia.

À luz das peculiaridades epidemiológicas acima configuradas, postulam-se dois meca- nismos determinantes da manutenção dos rotavírus nessas populações indígenas, justificando-se os expressivos índices no tocante à prevalência de anticorpos. Um deles seria representado por introduções esporádicas desses enteropatógenos nas populações sob estudo, oriundos do homem urbano. O outro, decorrente do possível papel que animais silvestres desempenhariam como reservatórios dos rotavírus, expondo, pois, os silvícolas à infecção. A título de corroborar essa última hipótese, citem-se os achados de Linhares et al. (1986a), relativos ao isolamento desses agentes em fezes obtidas de marsupiais capturados na Serra dos Carajás, Pará, em área de mata virgem.

\section{Aspectos clínicos das gastroenterites por rotavírus: breves considerações}

O caráter severo dos episódios diarréicos associados aos rotavírus é de recon hecimento universal, identificando-se maior impacto nos países do Terceiro Mundo, onde despontam como agravantes a desnutrição e os simultâneos processos infecciosos envolvendo outros enteropatógenos (Bern et al., 1992; Oliveira \& Linhares, 1999). Em geral, o quadro clínico clássico se caracteriza pelo início abrupto com vômitos e febre alta, sobrevindo diarréia profusa. Instala-se com freqüência a desidratação do tipo isotônica, não raro daí decorrendo o óbito (Kapikian \& Chanock, 1996). No Brasil, as investigações clínico-epidemiológicas conduzidas até então sustentam, invariavelmente, a maior gravidade de que se reveste a gastroenterite causada pel os rotavírus (Coiro et al., 1985; Linhares et al., 1989a; Linhares, 1997; Gusmão et al., 1999; Oliveira \& Linhares, 1999).

No Brasil, denota-se a maior expressão clínica dos episódios de diarréia relacionados aos rotavírus, se comparados àqueles por outros patógenos, tanto na comunidade como no âmbito hospitalar. À luz dessa comparação, e a título de exemplo, registrem-se os achados de Linhares et al. (1989a), indicando a maior freqüência de (a) evacuações líquidas, (b) vômitos, (c) náuseas, (d) cólicas abdominais e (e) febre entre crianças infectadas pelos citados vírus no seio comunitário. Nos hospitais, por outro lado, os parâmetros clínicos (a) febre, (b) vômitos e (c) desidratação prevaleceram amplamente nas diarréias associadas aos rotavírus, com base em recente análise procedida por Gusmão et al. (1999) em Belém, Pará.

O uso rotineiro no país da fórmula reidratante oral, preconizada pela Organização Mundial de Saúde (OMS), tem-se revelado prática 
altamente eficaz no combate à diarréia aguda, e de ampla aceitação. Estudos levados a efeito no nordeste brasileiro, por exemplo, demonstraram a maior eficácia da reidratação oral em relação à intravenosa, se analisados os quadros de diarréia infantil aguda, aí incluindo-se aqueles causados por rotavírus (McLean et al., 1982).

Características da imunidade para rotavírus em populações urbanas brasileiras

São limitadas as informações relativas à resposta imune nas infecções por rotavírus, quer no tocante à prevalência de anticorpos, quer quanto à dinâmica de aquisição da imunidade. Estudos dirigidos ao primeiro aspecto se desenvolveram nas regiões norte (Linhares et al., 1983a), central (Ishak et al., 1984), e sudeste (Salles-Gomes et al., 1983; Azeredo et al., 1989) do Brasil. No contexto dessas investigações soroepidemiológicas, observou-se que aproximadamente $70 \%$ das crianças, já aos 4- 5 anos de idade, infectaram-se por rotavírus, em consonância com achados de inúmeros outros estudos no mundo (Kapikian \& Chanock, 1996).

Durante estudo prospectivo desenvolvido na região Norte (Linhares et al., 1989b) se denotou persistência dos anticorpos maternos, transferidos passivamente, ao longo do primeiro trimestre de vida. Aos 6-7 meses observaram-se os mais baixos índices de positividade, sobrevindo elevação gradual a partir do primeiro ano. Aos 34 meses de vida, $80 \%$ das crianças investigadas se revelavam positivas quanto à presença de imunoglobulina G sérica para rotavírus, com base em procedimentos imunoenzimáticos. Num contexto comparativo, assinale-se que resultados similares emergiram de recente investigação conduzida em Recife, Pernambuco, onde se observou que $80 \%$ das crianças, aos dois meses de idade, ainda preservavam anticorpos oriundos da mãe (Andrade et al., 1996). Tais observações, convém ressaltar, assumem relevância quanto à implementação das futuras estratégias de vacinação no país. Com efeito, postula-se que uma eventual administração precoce (primeiros três meses) da vacina incorra em possíveis fenômenos de interferência mediados por anticorpos maternos residuais, sob elevados títulos no soro (Bresee et al., 1999).

A determinação da resposta imune frente aos diferentes sorotipos de rotavírus do grupo A se restringiu a algumas investigações levadas a efeito em Belém. A disponibilidade dos soros coletados das crianças participantes do estudo
Iongitudinal em Belém (Linhares et al., 1989a) ensejou o exame da resposta imune na vigência da infecção primária por rotavírus (Arias et al., 1994). Os achados daí resultantes assim se resumem: a) o sorotipo G1 induz, em geral, reação tipicamente homotípica; e b) os tipos G2 e G4, por sua vez, além da indução dos anticorpos homólogos, estimulam a síntese de anticorpos (heterotípicos) para o G1. Dessa análise sorológica coube postular que a indução de resposta imune heteróloga provavel mente se constitui em propriedade intrínseca da amostra viral. Ainda no tocante à imunidade natural específica para cada tipo, citem-se as conversões sorológicas detectadas ao longo do primeiro semestre de vida, durante estudo com uma vacina contra rotavírus em Belém : G1, 10\%; G2/ G3, 5\%; e G4, 7,5\% (Linhares et al., 1996). Tais indicadores indiretos da infecção recente consubstanciam dados pregressos quanto à ampla margem de suscetíveis aos seis meses de idade.

São controversos os achados relativos à eventual proteção contra as diarréias por rotavírus, conferida por anticorpos maternos transferidos passivamente via al eitamento natural. Esse efeito protetor não foi nítido $(p=0,21)$, por exemplo, em estudo prospectivo envolvendo crianças habitantes da periferia de Belém, na década de 80 (Linhares et al., 1989a). Em contrapartida, revelou-se notório $(p<0,05) o$ potencial protetor do leite materno no âmbito de recente investigação dirigida a enfermarias pediátricas de um hospital público da cidade (Gusmão et al., 1999). Essa divergência suscita a hipótese de que tal proteção se manifesta apenas na vigência de quadros clínicos mais graves, predominantes no seio hospitalar.

Parecem únicas no país as observações de Stephens et al. (1994), Rio de Janeiro, quanto ao papel da imunidade celular nas infecções por rotavírus. Esses investigadores, utilizando modelo experimental murino, demonstraram que a suscetibilidade dos camundongos recém-nascidos sob análise se condicionava à elevada proporção de células T no intestino desses animais, caracterizadas como CD8+e/ ou CD4+HCD8+.

\section{Prevenção e controle}

Prevalece amplo consenso, atualmente, de que o efetivo controle das gastroenterites por rotavírus se condiciona ao advento de uma vacina eficaz para uso corrente ao longo do primeiro semestre de vida (Bresee et al., 1999; Linhares \& Bresee, submetido). Tal asserção se fundamenta na singularidade que permeia a epide- 
miologia das infecções por esses vírus, evidenciada pelo fato de as taxas de incidência da doença nos países desenvolvidos e naqueles em desenvolvimento serem comparáveis. Deduz-se, por conseguinte, que eventuais intervenções na esfera da saúde pública, como o acesso amplo à água potável e a implementação de medidas visando ao saneamento básico, resultarão em impacto inexpressivo no que concerne à morbidade associada às diarréias por rotavírus (Bresee et al., 1999; Linhares \& Bresee, submetido).

Estudo de campo com uma vacina tetravalente contra rotavírus em Belém, Pará

A primeira avaliação de uma "candidata" à vacina contra rotavírus no Brasil transcorreu na primeira metade dos anos 90, em Belém, Pará (Linhares et al., 1996). O imunizante empregado consistia em preparação tetravalente, reunindo rotavírus de origens símia e humana, desenvolvida no National Institutes of Health, Bethesda, Maryland, Estados Unidos da América (Midthun et al., 1985). A vacina em questão, originalmente designada rhesus-human reassortant rotavirus tetraval ent vaccine, RRV-TV, reúne quatro cepas atenuadas distintas. Em síntese, assim se apresenta a composição: a) três amostras com especificidades antigênicas para G1, G2 e G4, obtidas por reestruturação genômica in vitro envolvendo rotavírus de origens humana e símia (RRV); e b) a própria cepa RRV, homóloga ao G3. O produto, designado Rotashield, mereceu licença pela Food and Drug Administration (FDA), Estados Unidos, em agosto de 1998, para uso rotineiro via oral, três doses (2, 4 e 6 meses), nesse país (Bresee et al., 1999).

Em Belém, a RRV-TV, na concentração de $4 \mathrm{x}$ 104 plaque-forming units, pfu/ dose foi avaliada no tocante à sua inocuidade, imunogenicidade e eficácia, fundamentado em estudo prospectivo ao longo de dois anos. O teste envolveu 540 crianças a quem se administraram, sob códigos, três doses de vacina ou placebo, em iguais proporções, aos 1o, 3o e 5o meses de vida (Linhares et al., 1996). Os efeitos colaterais atribuídos à RRV-TV se revelaram inexpressivos, restringindo-se a hipertermia leve detectada 3 a 5 dias após administrar-se a primeira dose, em apenas 3\% dos indivíduos vacinados. Observou-se indução satisfatória de imunoglobulinas séricas antirotavírus da classe IgA, refletida em conversões sorológicas, uma vez completo o esquema vacinal, de $60 \%$ e $33 \%$ nos grupos de crianças que receberam vacina e placebo, respectivamente. Quanto aos anticorpos neutralizantes específicos para os tipos G1, G2,
G3 e G4, tais soroconverões não excederam $20 \%$; aliás, padrão de resposta imune também observado em outros estudos no mundo (Midthun \& Kapikian, 1996). Considerados os 24 meses de vigilância das diarréias agudas, registrou-se eficácia global de $35 \%$. No primeiro ano, contudo, a taxa de proteção alcançou $60 \%$, quando predominava o tipo G1, decaindo sensivelmente para $12 \%$ ao longo do segundo período de acompanhamento. Digno de nota foi o expressivo nível protetor oferecido pela vacina, $80 \%$, em relação ao número médio diário de evacuações líquidas igual ou superior a seis, parâmetro nitidamente indicativo de gravidade.

Reanálise da eficácia em Belém, de acordo com a gravidade da diarréia

Os achados originais no que concerne à eficácia da RRV-TV mereceram recente reavaliação, com base na gravidade dos episódios diarréicos (Linhares et al., 1999). Dessa análise emergiram indicadores quanto à efetiva proteção conferida pela vacina frente aos quadros mais graves de gastroenterite por rotavírus. Com efeito, observou-se que três doses da vacina determinam um "gradiente" de proteção que varia de 0 a $75 \%$, de acordo com as faixas de escores clínicos atribuídas aos episódios, como segue: leves, 0 - 8; moderados/graves, 9 - 14; e muito graves, $>14$ (Flores et al., 1987). Note-se (Figura 3) que a proteção mais expressiva se registrou contra essa última categoria, revelando-se comparável aos índices alcançados em outros países, mesmo onde se utilizou tal imunizante em concentração mais elevada (4 × 105 pfu/ dose) (Bernstein et al., 1995; Rennels et al., 1995; Joensuu et al., 1997; Pérez-Schael et al., 1997; Santosham et al., 1997). Os resultados oriundos dessa investigação indicaram a necessidade de futuros estudos com a RRV-TV nos países em desenvolvimento, adotando-se o regime de vigilância passiva hospitalar dos episódios diarréicos (catchment trial).

\section{O recente advento da intussuscepção} como efeito colateral da RRV-TV nos

Estados Unidos: possíveis reflexos nas futuras estratégias de vacinação no Brasil

Em junho/julho de 1999, o Center for Diseases Control and Prevention (CDC), Atlanta, Georgia, Estados Unidos, determinou a suspensão temporária quanto ao uso da RRV-TV em território americano, com base em relatos sobre a ocorrência de intussuscepção entre 15 crianças vacinadas (CDC, 1999a). À mesma época, a Wyeth LederleVaccines, em consonância com 
Figura 3

Eficácia da RRV-TV (4 x $10^{4}$ pfu/dose) em Belém, Pará, frente aos quadros muito graves de gatroenterite por rotavírus, e comparação com os níveis protetores alcançados na Venezuela, Estados Unidos (três estudos) e Finlândia. Adaptado de Linhares et al. (1999).

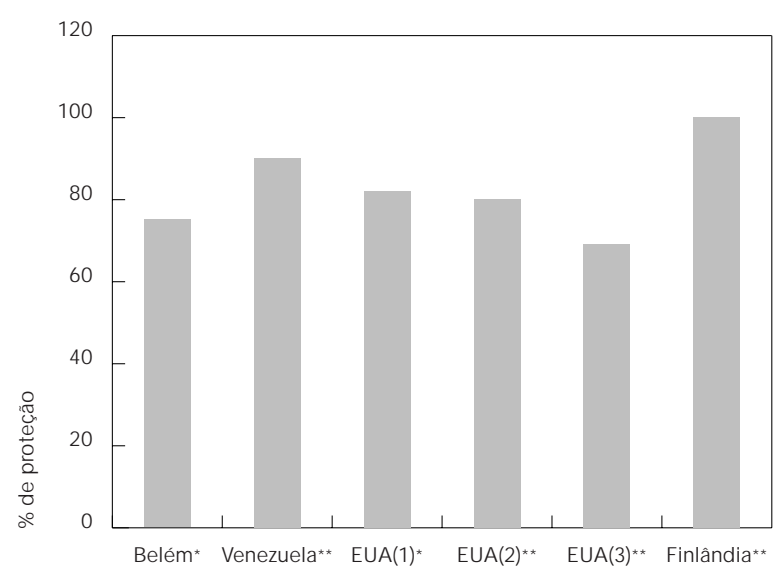

* baixa concentração; ** alta concentração.

recomendações emanadas da própria FDA, assumiu a iniciativa de interromper a distribuição do imunizante, seja para vacinação corrente nos Estados Unidos, seja com vistas aos estudos de campo programados pela OMS. (Destaquese nesse contexto teste de campo caracterizado como de "fase II", em Belém, originalmente planejado para início em agosto do mesmo ano).

Alguns meses após (outubro de 1999) a decisão acima configurada, o Advisory Committee on Immunization Practices (ACIP), Estados Unidos, fundamentado em ampla análise acerca do tema em tela, optou por cancelar a recomendação de uso da RRV-TV (CDC, 1999b). No curso dessa revisão, identificaram-se 91 casos daquele raro processo obstrutivo intestinal, uma vez já administradas aproximadamente 1,5 miIhão de doses a crianças americanas. Ressaltese a conclusão de que o risco se revelou mais expressivo do 3o ao 7o dias subseqüentes à administração da 1a dose.

Não obstante a total reversão de todo um processo de controle das gastroenterites por rotavírus nos Estados Unidos, a própria ACIP estabeleceu que a supracitada decisão não se aplica a outros países, particularmente os do Terceiro Mundo, onde o impacto da mortalidade é marcante.

O inusitado registro de intussuscepção entre crianças vacinadas com a Rotashield nos
Estados Unidos suscita complexo dilema ético quanto ao futuro uso dessa vacina nos países em desenvolvimento. A título de reflexão sobre o assunto, note-se que naquele país apenas 20-40 crianças morrem, ao ano, acometidas de diarréia por rotavírus. Em contrapartida, são 15.000 a 30.000 mortes em Bangladesh, no mesmo intervalo de tempo (Glass et al., 1996; Bresee et al., 1999). No Brasil, estimativas conservadoras sugerem a ocorrência de quase 2.000 mortes anuais associadas à gastroenterite por esses vírus entre crianças de baixa idade ( $\mathrm{Li}$ nhares et al., 1983b; DATASUS, 1998).

À luz de dados oficiais (DATASUS, 1998) registraram-se, em 1998, 211.741 hospitalizações por doença infecciosa intestinal no Brasil, entre crianças de 0 a 1 ano de idade, estimando-se que 1/ 3 (70.580) dessas situações se associe aos rotavírus. Paralelamente, considerados mesmos período e faixa etária, figuram 121 admissões por intussuscepção. Daí depreender-se que os benefícios de uma eventual utilização rotineira da vacina contra rotavírus no Brasil suplantariam expressivamente o eventual risco representado pela intussuscepção.

Durante recente reunião na OMS ( 9 a 11 de fevereiro de 2000), intitulada Future Direction for Rotavirus Vaccine Research in Developing Countries, considerou-se, em bases estritamente éticas, a possibilidade de retomada dos estudos de campo com a RRV-TV nos países em desenvolvimento. $O$ eventual reinício de tais estudos, entretanto, inclusive no Brasil, requer a adoção de medidas estritas visando à detecção dos possíveis efeitos colaterais da vacina, mormente a intussuscepção, o que pressupõe a permanente e direta supervisão à conta de pediatras experientes.

Como alternativas à Rotashiel d despontam, presentemente, duas promissoras "candidatas" a vacina contra rotavírus, quais sejam a 89-12, de origem humana, e outra preparação geneticamente reestruturada, reunindo cepas de origens bovina e humana (Bernstein et al., 1999; Clements-M ann et al., 1999). Convém assinaIar, entretanto, que um eventual uso corrente desses imunizantes requer pelo menos mais 6 a 7 anos de investigação, já que os resultados disponíveis quanto à performance ainda refletem estágio bastante incipiente de avaliação.

\section{Comentários finais}

Decorridas duas décadas de estudos epidemiológicos acerca das infecções por rotavírus no Brasil, são nítidos os indicadores quanto à relevância que assumem esses agentes na gênese 
das gastroenterites infantis agudas, particularmente aquelas dotadas de maior gravidade.

À semelhança do que se configura em escala universal, o controle da doença determinada pelo agente etiológico em questão no país se condiciona à disponibilidade de uma vacina particularmente eficaz contra os episódios diarréicos de maior expressão clínica, presente a desi dratação. O imunizante que se revelava até então mais promissor era a RRV-TV, elaborada com o propósito básico de proteger contra os quatro tipos predominantes de rotavírus, a saber, G1, G2, G3 e G4. O proposto esquema de uso aos 2, 4 e 6 meses de idade, a par das chances de administrá-la concomitantemente à antipólio, representam aspectos vantajosos face à perspectiva de sua eventual incorporação ao calendário básico de imunizações no Brasil. Um fator limitante a sua utilização, no entanto, é representado pelo elevado custo, presentemente estimado em U $\$ 30.00$ por dose.

Conquanto sejam múltiplos os dados pertinentes à incidência das infecções por rotavírus, em particular os que retratam o panorama no âmbito dos hospitais, urge que se implemente, nesse contexto, o estabelecimento de uma rede nacional visando à vigilância epidemiológica sistemática. A adoção de um protocolo técnico-operacional padronizado ensejaria caracterizar com precisão e representatividade o impacto da doença no país, realçando os aspectos da morbidade e mortalidade.

Dadas as peculiaridades antigênicas e genotípicas das amostras de rotavírus prevalentes em vários estados, sustenta-se como imperativo monitorar sistematicamente os tipos circulantes. Além da significativa proporção correspondente ao genótipo G5, ressaltem-se as múltiplas infecções caracterizadas como "mistas", condição que favorece as reestruturações genéticas in vivo, e, conseqüentemente, a emergência de cepas não usuais. À luz dessas características singulares, postula-se, até, a eventual necessidade de uma vacina que contemple composição diferenciada para o Brasil.

O único teste de campo até então levado a efeito no país com a RRV-TV, em sua baixa concentração, ofereceu resultados promissores no tocante à eficácia contra os episódios mais graves de gastroenterite por rotavírus. Não obstante, investigações adicionais envolvendo a vacina em sua fórmula mais concentrada são necessárias. A proposta de estudo ulterior em Belém contempla a análise dos efeitos colaterais, bem como da resposta imune frente a três regimes vacinais distintos. (Interrompeu-se temporariamente esse trial em julho de 1999, face à ocorrência de intussuscepção entre crianças vacinadas com a Rotashield nos Estados Unidos). Sustenta-se ainda a possibilidade de conduzir investigação dirigida à eficácia da RRVTV (4 x 105 pfu/dose) no Brasil, com base em vigilância passiva dos episódios diarréicos no âmbito hospitalar (catchment trial).

O recente registro de intussuscepção como efeito colateral da RRV-TV nos Estados Unidos reserva sérias implicações quanto à aceitabilidade da vacina nos países em desenvolvimento, inclusive o Brasil, embora se admita que os benefícios advindos da vacinação suplantem expressivamente eventuais riscos. A emergência dessa condição clínica, não identificada antes nos vários testes de campo, justifica duas recomendações: a) ampliar o conhecimento sobre a epidemiologia desse processo obstrutivo no país; e b) adequar protocolos de (eventuais) futuros estudos com vistas à sua pronta identificação.

Uma vez que, junto às mães, a percepção quanto à importância da vacina contra rotavírus não se prenuncia como nítida, impõe-se intenso trabalho educativo face à perspectiva de sua introdução. Com efeito, dos 30 a 50 episódios de diarréia que acometem a criança nos primeiros cinco anos de vida, apenas um (talvez dois) se associam aos rotavírus, daí o efetivo impacto vir a afigurar-se mais evidente entre médicos e autoridades de saúde. A complexidade dessa tarefa tende a avultar-se consideravelmente, mercê do "estigma" gerado pela intussuscepção entre recipientes da vacina nos Estados Unidos.

Outro efeito danoso da reação adversa mencionada nos dois parágrafos precedentes se refletiu na produção da RRV-TV nos Estados Unidos, interrompida desde julho de 1999. Com isso, exploram-se alternativas quanto a fabricála em outros países, especialmente os do Terceiro Mundo, na expectativa de sua eventual utilização em larga escala. Com esse propósito recomenda-se, por exemplo, o futuro aproveitamento (e adaptação) da infra-estrutura ora de suporte à produção da vacina antipólio em alguns países da América Latina, particularmente o Brasil (WHO/CDC/CVI, 1997).

Eventuais outros estudos de eficácia no Brasil, envolvendo novas candidatas à vacina contra rotavírus (89-12, tetravalente bovino-humana etc.), seriam plenamente justificáveis face à magnitude epidemiológica que assumem as infecções por esses agentes virais em âmbito nacional. 


\section{Agradecimentos}

Formulamos nossos agradecimentos ao Dr. Roberto Men Fernandes, Centro Nacional de Epidemiologia, Fundação Nacional de Saúde, Ministério da Saúde, pelo inestimável suporte proporcionado quanto ao acesso a dados de hospitalizações e mortalidade por diarréia infantil no país.

\section{Referências}

ANDRADE, G. P.; LIMA, L. R. A. V.; HOSHINOSHIMIZU, S.; OLIVEIRA, M. I.; MENDONÇA, R. Z.; HÁRSI, C. M. \& STEWIEN, K. E., 1996. Humoral immunity patterns based on antibody reactivity to rotavirus antigens in Brazilian children under 5 years of age. Journal of Medical Virology, 49:212-217

ARIAS, C. F.; LOPEZ, S.; MASCARENHAS, J. D. P. ROMERO, P.; CANO, P.; GABBAY, Y. B.; DE FREITAS, R. B. \& LINHARES, A. C., 1994. Neutralizing antibody immune response in children with primary and secondary rotavirus infections. Clinical Diagnostic Laboratory Immunology, 1:89-94.

AZEREDO, R. S.; LEITE, J. P. G.; PEREIRA, J. H. G.; VIDAL, M. N.; SUTMOLLER, F.; MAURICE, Y. \& SCHATZM AYR, H. G., 1989. A serological investigation of rotavirus infections in a shanty town population in Rio de Janeiro. Revista do Instituto de Medicina Tropical de São Paulo, 31:262-266.

BEARDS, G. M .; DESSELBERGER, U . \& FLEWETT, T. H., 1989. Temporal and geographical distribution of human rotavirus serotypes, 1983 to 1988 . Journal of Clinical Microbiology, 27:2827-2833.

BERN, C.; MARTINES, J.; DE ZOYSA, I. \& GLASS, R. I., 1992. The magnitude of the global problem of diarrhoeal disease: A ten-year update. Bulletin of theWorld Health Organization, 70:705-714.

BERNSTEIN, D. I.; GLASS, R. I.; RODGERS, G.; DAVIDSON, B. L.; SACK, D. A. \& US ROTAVIRUS VACCINE EFFICACY GROUP, 1995. Evaluation of rhesus rotavirus monovalent and tetravalent reassortant vaccines in US children. JAMA, 273:11911196.

BERNSTEIN, D. I.; SACK, D. A.; ROTHSTEIN, E.; REISINGER, K.; SMITH, V. E.; O'SULLIVAN, D.; SPRIGGS, D. R. \& WARD, R. L., 1999. Efficacy of live, attenuated, human rotavirus vaccine $89-12$ in infants: A randomised placebo-controlled trial. Lancet, 354:287-290.

BISHOP, R. F.; DAVIDSON, G. P.; HOLMES, I. H. \& RUCK, B. J., 1973. Virus particles in epithelial cells of duodenal mucosa from children with viral gastroenteritis. Lancet, 2:1281-1283.
BLAKE, P. A.; RAM OS, S.; MCDONALD, K. L.; RASSI, V.; GOMES, T. A.; IVEY, C.; BEAN, N. H. \& TRABULSI, L. R., 1993. Pathogen-specific risk factors and protective factors for acute diarrheal disease in urban Brazilian infants. Journal of Infectious Diseases, 167:627-632.

BRESEE, J. S.; GLASS, R. I.; IVANOFF, B. \& GENTSCH, J. R., 1999. Current status and future priorities for rotavirus vaccine development, evaluation and implementation in developing countries. Vaccine, 17:2207-2222.

BRIDGER, J. C.; PEDLEY, S. \& MCCRAE, M. A., 1986. Group $C$ rotaviruses in humans. Journal of Clinical Microbiology, 23:760-763.

CANDEIAS, J. A.; RÁCZ, M. L.; TRABULSI, L. R. \& MURAKOWSKY, J., 1989. Relative prevalence of rotavirus diarrhoea in children attending outpatient departments of hospitatls and general practitioners in São Paulo, Brazil. Journal of Diarrhoeal Diseases Research, 7:24-27.

CARDOSO, D. D.; DE BRITO, W. M.; MARTINS, R. M.; KITAJIMA, E. W.; SOUZA, M. P.; BARBOSA, A. J.; DE OLIVEIRA, S. A. \& RASCOPI, S. B., 1989. Presença de rotavírus e adenovírus em amostras fecais de crianças com gastroenterite na cidade de Goiânia. Revista da Sociedade Brasileira de Medicina Tropical, 22:67-71.

CARDOSO, D. D.; MARTINS, R. M.; KITAJIMA, E. W.; BARBOSA, A. J.; CAM AROTA, S. C. \& AZEVEDO, M. S., 1992. Rotavírus e adenovírus em crianças de 0-5 anos hospitalizadas com ou sem gastroenterite em Goiânia-GO, Brasil. Revista do Instituto de Medicina Tropical de São Paulo, 34:433-439.

CDC (Centers for Disease Control and Prevention), 1999a. Intussusception among recipients of rotavirus vaccine - United States, 1998-1999. MMWR, 48:577-581.

CDC (Centers for Disease Control and Prevention), 1999b. Withdrawal of rotavirus vaccine recommendation. MMWR, 48:1007.

CLEMENTS-MANN, M. L.; MAKHENE, M. K. MRUKOWICZ, J.; WRIGHT, P. F.; HOSHINO, Y.; MIDTHUN, K.; SPERBER, E.; KARRON, R. \& 
KAPIKIAN, A. Z., 1999. Safety and immunogenicity of live attenuated human-bovine (UK) reassortant rotavirus vaccines with VP7-specificity for serotypes 1, 2, 3 or 4 in adults, children and infants. Vaccine, 17:2715-2725.

COIRO, J. R. R.; DE ALMEIDA-NETO, A. J.; HEUSER, M. C. F.; BENDATI, M. M. A. \& VASCONCELOS, V. L., 1985. Acute enteritis associated with rotavirus presence in Brazilian children: Evaluations on the prevalence, therapy and age group. Journal of $\mathrm{Di}$ arrhoeal Diseases Research, 3:78-83.

COOK, S. M.; GLASS, R. I.; LeBARON, C. H. \& HO, M. S., 1990. Global seasonality of rotavirus infections. Bulletin of theWorld Health Organization, 68:171-177.

COOKE, S. J.; CLARKE, I. N.; FREITAS, R. B.; GABBAY, Y. B. \& LAMBDEN, P. R., 1992. The correct sequence of the porcine group $\mathrm{C} /$ Cowden rotavirus major inner capsid protein shows close homology with isolates from Brazil and the U. K. Virology, 190:531-537.

COX, M. J.; JAMES, V. L. A.; AZEVEDO, R. S.; MASSAD, E. \& MEDLEY, G. F., 1998. Infection with group C rotavirus in a suburban community in Brazil. Tropical Medicine and International Health, 3: 891-895.

DATASUS (Departamento de Informática do SUS), 1997. Dados sobre Hospitalizações e Mortalidade por Diarréia em Crianças. Brasília: Ministério da Saúde.

DATASUS (Departamento de Informática do SUS), 1998. Dados sobre Hospitalizações e Mortalidade por Diarréia em Crianças. Brasília: Ministério da Saúde.

DE CASTRO, L.; RODRIGUES, D. P.; FLAUZINO, R.; M OURA, M. \& LEITE, J. P., 1994. An outbreak of diarrhea associated with rotavirus serotype 1 in a day care nursery in Rio de Janeiro, Brazil. Memórias do Instituto Oswal do Cruz, 89:5-9.

DE ZOYSA, I. \& FEACHEM, R. G., 1985. Interventions for the control of diarrhea diseases among young children: Rotavirus and cholera immunization. Bulletin of the World Health Organization, 63: 569-583.

FLEWETT, T. H. \& WOODE, G. N., 1978. The rotaviruses. Brief review. Archives of Virology, 57:1-23.

FLORES, J.; PEREZ-SCHAEL, I.; GONZALES, M.; GARCIA, D.; PEREZ, M.; DAOUD, N.; CUNTO, W.; CHANOCK, R. M. \& KAPIKIAN, A. Z., 1987. Protection against severe rotavirus diarrhoea by rhesus rotavirus vaccine in Venezuelan infants. Lancet, 1:882-884.

GABBAY, Y. B.; JIANG, B.; OLIVEIRA, C. S.; MASCARENHAS, J. D. P.; LEITE, J. P. G.; GLASS, R. I. \& LINHARES, A. C., in press. An outbreak of group $C$ rotavirus gastroenteritis among children attending a day-care center in Belém, Brazil. Journal of Diarrhoeal Diseases Research.

GABBAY, Y. B.; MASCARENHAS, J. D. P.; LINHARES, A. C. \& FREITAS, R. B., 1989. Atypical rotavirus among diarrhoeic children living in Belém, Brazil. Memórias do Instituto Oswal do Cruz, 84:5-8.

GATTI, M. S.; RICCI, L. C.; SERAFIM, M. B. \& DE CASTRO, A. F., 1989. Incidência de Escherichia coli enterotoxigênica (ETEC), rotavírus e Clostridium perfringens de casos de diarréia em crianças, na região de Campinas, SP, Brasil. Revista do Instituto de Medicina Tropical de São Paulo, 31:392-398.

GLASS, R. I.; LANG, D. R.; IVANOFF, B. N. \& COMPANS, W., 1996. Introduction: Rotavirus - From basic research to a vaccine. Journal of Infectious Diseases, 174 (Sup. 1):S1-S2.

GOMES, T. A.; RASSI, V.; MacDONALD, K. L.; RAMOS, S. R. T. S.; TRABULSI, L. R.; VIEIRA, M. A.; GUTH, B. E. C.; CANDEIAS, J. A. N.; IVEY, C.; TOLEDO, M. R. F. \& BLAKE, P., 1991. Enteropathogens associated with acute diarrheal diseases in urban infants in São Paulo, Brazil. Journal of Infectious Diseases, 164:331-337.

GOUVEA, V.; DE CASTRO, L.; TIMENETSKY, M. C.; GREENBERG, H. \& SANTOS, N., 1994. Rotavirus serotype G5 associated with diarrhea in Brazilian children. Journal of Clinical Microbiology, 32: 1408-1409.

GOUVEA, V. \& SANTOS, N., 1999. Rotavirus serotype G5: An emerging cause of epidemic childhood diarrhoea (letter). Vaccine, 17:1291-1292.

GUERRANT, R. L.; KIRCHHOFF, L. V.; SHIELDS, D. S.; NATIONS, M. K.; LESLIE, J.; DE SOUZA, M. A.; ARAUJO, J. G.; CORREIA, L. L.; SAUER, K. T.; MCCLELLAND, K. E.; TROWBRIDGE, F. L. \& HUGHES, J. M., 1983. Prospective study of diarrheal illness in Northeastern Brazil: Patterns of disease, nutrutional impact, etiologies and risk factors. Journal of Infectious Diseases, 148:986-997.

GUSMÃO, R. H. P.; MASCARENHAS, J. D. P.; GABBAY, Y. B. \& LINHARES, A. C., 1994. Nosocomial transmission of an avian-like rotavirus strain among children in Belém, Brazil. Journal of Diarrhoeal Diseases Research, 12:129-132.

GUSMÃO, R. H. P.; MASCARENHAS, J. D. P.; GABBAY, Y. B.; LINS-LAINSON, Z.; RAMOS, F. L. P.; MONTEIRO, T. A. F.; VALENTE, S. A.; FAGUNDES-NETO, U. \& LINHARES, A. C., 1999. Rotavirus subgroups, G serotypes, and electrophoretypes in cases of nosocomial infantile diarrhoea in Belém, Brazil. Journal of Tropical Pediatrics, 45:81-86.

GUSMÃO, R. H. P.; MASCARENHAS, J. D. P.; GABBAY, Y. B.; LINS-LAINSON, Z.; RAM OS, F. L. P.; MONTEIRO, T. A. F.; VALENTE, S. A. \& LINHARES, A. C., 1995. Rotaviruses as a cause of nosocomial, infantile diarrhea in Northern Brazil: Pilot study. Memórias do Instituto Oswaldo Cruz, 90:743-749.

HOULY, C. A. P.; UCHOA, M. M. M.; ZAIDAN, A. M. E.; GOMES-NETO, A.; DE OLIVEIRA, F. M.; ATHAYDE, M. A. G.; ALMEIDA, M. L. F. M. \& PEREIRA, H. G., 1986. Electrophoretic study of the genome of human rotavirus from Maceió, Brazil. Brazilian Journal of Medical and Biological Research, 19:33-37.

INSTITUTE OF MEDICINE, 1986. The prospects for immunizing against rotavirus. In: New Vaccine Devel opments: Establishing Priorities. Diseases of Importance in Developing Countries, pp. 308-318, Washington, D.C.: National Academy Press.

ISHAK, R.; LINHARES, A. C.; GABBAY, Y. B.; ISHAK, M. O. \& CARDOSO, D. D., 1984. Soroepidemiologia de rotavírus em uma população infantil. Goiânia, Goiás, Brasil. Revista do Instituto de Medicina Tropical deSão Paulo, 26:280-284.

JOENSUU, J.; KOSKENNIEMI, E.; PANG, X.-L. \& VESIKARI, T., 1997. Randomised placebo-controlled trial of rhesus-human reassortant ro- 
tavirus vaccine for prevention of severe rotavirus gastroenteritis. Lancet, 350:1205-1209.

KAPIKIAN, A. Z. \& CHANOCK, R. M., 1996. Rotaviruses. In: Virology (B. N. Fields, D. M. Knipe \& P. M. Howley, eds.), pp. 1657-1708, Philadelphia: Lippincott-Raven Publishers.

LEITE, J. P. G.; ALFIERI, A. A.; WOODS, P. A.;GLASS, R. I. \& GENTSCH, J. R., 1996. Rotavirus G and P typing circulating in Brazil: Characterization by RTPC, probe hybridization, and sequence analysis. Archives of Virology, 141:2365-2374.

LINHARES, A. C., 1992. Epidemiologia das infecções diarréicas entre populações indígenas da Amazônia. Cadernos de Saúde Pública, 8:121-128.

LINHARES, A. C., 1997. Rotavirus infection in Brazil: Epidemiology, immunity, and potential vaccination. Brazilian Journal of Infectious Diseases, 1: 284-293.

LINHARES, A. C. \& BRESEE, J. S., (submetido). Rotavirus vaccines and vaccination in Latin America. Pan American Journal of Public Health.

LINHARES, A. C.; FERREIRA, F. S.; MAUÉS, B. C.; BENCHIM OL, J. A. \& GABBAY, Y. B., 1983a. Prevalência de anticorpos para rotavírus em crianças diarréicas de Belém, Brasil. Revista da Fundação SESP, 28:95-105.

LINHARES, A. C.; GABBAY, Y. B.; FREITAS, R. B. \& MASCARENHAS, J. D. P., 1988a. Reinfections and rotavirus serotypes in Belém, Brazil (Preliminary report). Revista do Instituto de Medicina Tropical deSão Paulo, 30:101-106.

LINHARES, A. C.; GABBAY, Y. B.; FREITAS, R. B.; TRAVASSOS-DA-ROSA, E. S.; MASCARENHAS, J. D. P. \& LOUREIRO, E. C. B., 1989a. Longitudinal study of rotavirus infections among children from Belém, Brazil. Epidemiology and Infection, 102: 129-145.

LINHARES, A. C.; GABBAY, Y. B.; MASCARENHAS, J. D. P.; FREITAS, R. B.; FLEWETT, T. H. \& BEARDS, G. M., 1988b. Epidemiology of rotavirus subgroups and serotypes in Belém, Brazil: A threeyear study. Annales del'Institut Pasteur/Nirologie, 139:89-99.

LINHARES, A. C.; GABBAY, Y. B.; MASCARENHAS, J. D. P.; FREITAS, R. B.; OLIVEIRA, C. S.; BELLESI, N \& MONTEIRO, T. A. F., 1992. Epidemiology of rotavirus gastroenteritis in the Amazon region and the need for a specific vaccine. Ciência eCultura, 44:154-157.

LINHARES, A. C.; GABBAY, Y. B.; MASCARENHAS, J. D. P.; FREITAS, R. B.; OLIVEIRA, C. S.; BELLESI, N.; MONTEIRO, T. A. F.; LINS-LAINSON, Z.; RAMOS, F. L. P. \& VALENTE, S. A., 1994. Estudo prospectivo das infecções por rotavírus em Belém, Pará, Brasil: Uma abordagem clínico-epidemiológica. Jornal de Pediatria, 70:220-225.

LINHARES, A. C.; GABBAY, Y. B.; M ASCARENHAS, J. D. P.; FREITAS, R. B.; OLIVEIRA, C. S., BELLESI, N.; MONTEIRO, T. A. F.; LINS-LAINSON, Z.; RAMOS, F. L. P. \& VALENTE, S. A., 1996. Immunogenicity, safety and efficacy of rhesus-human, reassortant rotavirus vaccine in Belém, Brazil. Bulletin of the World Health Organization, 74: 491-500.

LINHARES, A. C.; LANATA, C. F.; HAUSDORFF, W. P.; GABBAY, Y. B. \& BLACK, R. E., 1999. Reappraisal of the Peruvian and Brazilian lower titer tetravalent rhesus-human reassortant rotavirus vaccine efficacy trials: Analysis by severity of diarrhea. $\mathrm{Pe}$ diatric Infectious Diseases Journal, 18:1001-1006.

LINHARES, A. C.; MAGALHÃES-MOURA, J. M.; GABBAY, Y. B.; RABELO-MENDES, P. S. C.; MASCARENHAS, J. D. P. \& DE AZEVEDO, R. C., 1993. Rotavirus serotypes and electrophoretypes among children attending three paediatric hospitals in Belém, Brazil. Journal of Tropical Pediatrics, 39: 137-141.

LINHARES, A. C.; MASCARENHAS, J. D. P.; GUSMÃO, R. H. P.; LEITE, J. P. G.; GABBAY, Y. B. \& GENSTCH, J. R., s/d. Neonatal rotavirus infection in Belém, Northern Brazil: Nosocomial transmission of a P[6], G2 strain. [Manuscrito em preparação].

LINHARES, A. C.; MELO, V. R.; M ASCARENHAS, J. D. P.; GABBAY, Y. B. \& FREITAS, R. B., 1989b. Pattern of acquisition of rotavirus antibody in children followed up from birth to the age of three years. Revista da Sociedade Brasileira de Medicina Tropical, 22:25-29.

LINHARES, A. C.; MONÇÃO, H. C.; GABBAY, Y. B.; DE ARAÚJO, V. L. C.; SERRUYA, A. C. \& LOUREIRO, E. C. B., 1983b. Acute diarrhoea associated with rotavirus among children living in Belém, Brazil. Transactions of the Royal Society of Tropical Medicineand Hygiene, 77:384-390.

LINHARES, A. C.; PEREIRA, J. D. M .; NAKAUTH, C. M . \& GABBAY, Y. B., 1986a. Rotavirus infection in wild marsupials (Didelphis marsupialis) of the Amazon region. Transactions of the Royal Society of Tropical Medicineand Hygiene, 80:20-24.

LINHARES, A. C.; PINHEIRO, F. P.; FREITAS, R. B.; GABBAY, Y. B.; SHIRLEY, J. A. \& BEARDS, G. M., 1981. An outbreak of rotavirus diarrhea among a non-immune, isolated South American Indian community. American Journal of Epidemiology, 113:703-710.

LINHARES, A. C.; PINHEIRO, F. P.; SCHMETZ, C.; MÜLLER, G. \& PETERS, D., 1977. Rotavírus em Belém do Pará, Brasil. Revista do Instituto de Me dicina Tropical deSão Paulo, 19:278.

LINHARES, A. C.; PINHEIRO, F. P.; SCHMETZ, C.; MÜLLER, G.; PETERS, D. \& FREITAS, R. B., 1982. Rotavírus em Belém do Pará, Brasil (Estudo-piloto). Revista do Instituto de Medicina Tropical de São Paulo, 24:292-297.

LINHARES, A. C.; SALBÉ, E. V.; GABBAY, Y. B. \& REES, N., 1986b. Prevalence of rotavirus antibody among isolated South American Indian communities. American Journal of Epidemiology, 123:699-709.

MANGIA, A. H.; DUARTE, A. N.; DUARTE, R.; SILVA, L. A.; BRAVO, V. L. \& LEAL, M. C., 1993. Aetiology of acute diarrhoea in hospitalized children in Rio de Janeiro city, Brazil. Journal of Tropical Pediatrics, 39:365-367.

MASCARENHAS, J. D. P.; ARIAS, C. F.; PADILLA-NORIEGA, L.; LOPEZ, S.; GUSM ÃO, R. H. P.; GABBAY, Y. B. \& LINHARES, A. C., 1997. Characterization of rotavirus strains with unusual electrophoretic profiles. Memórias do Instituto Oswal do Cruz, 92: 771-774.

MASCARENHAS, J. D. P.; GABBAY, Y. B.; FREITAS, R. B. \& LINHARES, A. C., 1988. Distribuição temporal de perfis eletroforéticos de ácido nucléico de ro- 
tavírus em fezes de crianças em Belém, Pará. Memórias do Instituto Oswaldo Cruz, 83:415-419.

MASCARENHAS, J. D. P.; GUSMÃO, R. H. P.; BARARDI, C. R. M.; PAIVA, F. L.; SIMÕES, C. O.; GABBAY, Y. B.; MONTEIRO, T. A. F. \& LINHARES, A. C., 1999. Characterization of rotavirus $P$ genotypes circulating among paediatric inpatients in northern Brazil. Revista do Instituto de Medicina Tropical deSão Paulo, 41:165-170.

MASCARENHAS, J. D. P.; LINHARES, A. C.; GABBAY, Y. B.; FREITAS, R. B.; MENDEZ, E.; LOPEZ, S. \& ARIAS, C. F., 1989. Naturally occurring serotype 2, subgroup II rotavirus reassortants in Northern Brazil. Virus Research, 14:235-240.

MASCARENHAS, J. D. P.; PAIVA, F. L.; BARARDI, C. R. M.; GABBAY, Y. B.; SIM ÕES, C. O. \& LINHARES, A. C., 1998. Rotavirus $G$ and $P$ types in children from Belém, northern Brazil, as determined by RT-PCR: Occurrence of mixed $P$ type infections. Journal of Diarrhoeal Diseases Research, 16:8-14.

MATSUMOTO, K.; HATANO, M.; KOBAYASHI, K.; HASEGAWA, A.; YAM AZAKI, S.; NAKATA, S.; CHIBA, S. \& KIMURA, Y., 1989. An outbreak of gastroenteritis associated with acute rotavirus infection in schoolchildren. Journal of Infectious Diseases, 160:611-615.

MAUNULA, L.; SVENSSON, L. \& BONSDORFF, C. H., 1992. A family outbreak of gastroenteritis caused by group $C$ rotavirus. Archives of Virology, 124: 269-278.

MCLEAN, M.; BRENNAN, R.; HUGHES, J. M.; KORZENIOWSKI, O. M.; SOUZA, M. A.; ARAUJO, J. G.; BENEVIDES, T. M. \& GUERRANT, R. L., 1982. Etiología de la diarrea infantil y terapia de rehidratación oral en el nordeste de Brasil. Boletín dela Oficina Sanitaria Panamericana, 92:405-417.

MIDTHUN, K.; GREENBERG, H. B.; HOSHINO, Y.; KAPIKIAN, A. Z.; WYATT, R. G. \& CHANOCK, R. M., 1985. Reassortant rotaviruses as potential live rotavirus candidate vaccines. Journal of Virology, 53:949-954.

MIDTHUN, K. \& KAPIKIAN, A. Z., 1996. Rotavirus vaccines: An overview. Clinical Microbiology Reviews, 9:423-434

OLIVEIRA, C. S. \& LINHARES, A. C., 1999. Rotavírus: Aspectos clínicos e prevenção. Jornal de Pediatria, 75 (Sup. 1):S91-S102.

OLIVEIRA, C. S.; LINHARES, A. C.; BELLESI, N.; MASCARENHAS, J. D. P.; FREITAS, R. B.; GABBAY, Y. B. \& MONTEIRO, T. F., 1994. Tripla infecção por rotavírus em uma criança de Belém, Pará. Jornal de Pediatria, 70:240-242.

PEREIRA, H. G.; AZEREDO, R. S.; LEITE, J. P. G.; CANDEIAS, J. A. N.; RÁCZ, M. L.; LINHARES, A. C.; GABBAY, Y. B. \& TRABULSI, L. R., 1983a. Electrophoretic study of the genome of human rotaviruses from Rio de Janeiro, São Paulo and Pará. Journal of Hygiene, 90:117-125.

PEREIRA, H. G.; LEITE, J. P. G.; AZEREDO, R. S.; DE FARIAS, V. \& SUTM OLLER, F., 1983b. An atypical rotavirus detected in a child with gastroenteritis in Rio de Janeiro, Brazil. Memórias do Instituto Oswal do Cruz, 78:245-250.

PEREIRA, H. G.; LINHARES, A. C.; CANDEIAS, J. A. N. \& GLASS, R. I., 1993. National laboratory surveillance of viral agents of gastroenteritis in Brazil.
Bulletin of the Pan American Health Organization, 27:224-233.

PEREZ-SCHAEL, I.; GUNTINAS, M. J.; PEREZ, M.; PAGONE, V.; ROJAS, A. M.; GONZALEZ, R.; CUNTO, W.; HOSHINO, Y. \& KAPIKIAN, A. Z., 1997. Efficacy of the rhesus rotavirus-based quadrivalent vaccine in infants and young children in Venezuela. New England Journal of Medicine, 337: 1181-1187.

RÁCZ, M. L.; CANDEIAS, J. A. N.; TRABULSI, J. R. \& MURAKOWSKY, J., 1988. Diarrheal diseases in Brazil: Clinical features of rotavirus-associated gastroenteritis in children. European Journal of Epidemiology, 4:382-385.

RENNELS, M. B.; GLASS, R. I.; DENNEHY, P. H.; BERNSTEIN, D. I.; PICHICHERO, M. E.; ZITO, E. T.; MACK, M. E.; DAVIDSON, B. L.; KAPIKIAN, A. Z. \& UNITED STATES ROTAVIRUSVACCINE EFFICACY GROUP, 1995. Safety and efficacy of highdose rhesus-human reassortant rotavirus vaccines - Report of the national multicenter trial. Pediatrics, 97:7-13.

SALLES-GOMES, L. F.; SAKUMA, M. E.; CURTI, S. P. \& TAKIGUTI, C. K., 1983. Freqüência de anticorpos para rotavírus em habitantes da cidade de São Paulo em 1980-1982. Revista Paulista de Medicina, 101:127-132.

SANTOS, N. \& GOUVEA, V., 1997. Infecções por rotavírus: Aspectos atuais. Jornal Brasileiro de Patologia, 33:94-102.

SANTOS, N.; LIMA, R. C. C.; PEREIRA, C. F. A. \& GOUVEA, V., 1998. Detection of rotavirus types G8 and G10 among Brazilian children with diarrhea. Journal of Clinical Microbiology, 36:2727-2729.

SANTOS, R. V.; LINHARES, A. C. \& COIMBRA J r., C. E. A., 1991. Estudos epidemiológicos entre grupos indígenas de Rondônia. IV. Inquérito sorológico para rotavírus entre os Suruí e Karitiana. Revista deSaúdePública, 25:230-232.

SANTOSHAM, M.; MOULTON, L. H.; REID, R.; CROLL, J.; WEATHERHOLT, R.; WARD, R.; FORRO, J .; ZITO, E.; MACK, M.; BRENNEMAN, G. \& DAVIDSON, B., 1997. Efficacy and safety of high-dose rhesus-human reassortant rotavirus vaccine in native American populations. Journal of Pediatrics, 131:632-638.

SILVA, K. T. F.; LINHARES, A. C. \& GABBAY, Y. B., 1984. Microssurtos familiares de gastroenterite aguda associada a rotavírus na área de Belém, Pará. Revista da Fundação SESP, 29:129-136.

SOUZA, D. F. C.; KISIELIUS, J. J.; UEDA, M.; GABBAY, Y. B.; CARM ONA, R. C. C.; TIMENETSKY, M. C. S. T.; MASCARENHAS, J. D. P.; TAKIMOTO, S. \& TANAKA, H., 1998. An outbreak of group C rotavirus gastroenteritis among adults living in Valentim Gentil, São Paulo state, Brazil. Journal of Diarrhoeal Diseases Research, 16:59-65.

STEPHENS, P. R. S.; BERTHO, A. L.; LUZ, N. C.; SANTIAGO, M. A. \& KUBELKA, C. E., 1994. Characterization of $C D_{4}$ and $C D_{8}$ bearing cells in intestines of rotavirus susceptible (suckling) and resistant (adult/ weanling) mice by flow cytometry. Ciência eCultura, 46:182-184.

STEWIEN, K. E.; DA CUNHA, L. C.; ALVIM, A. C.; REIS-FILHO, S. A.; ALVIM, M. A.; BRANDÃO, A. A. \& NEIVA, M. N., 1991. Rotavirus associated diar- 
rhea during infancy in the city of S. Luis (MA), Brazil: A two-year longitudinal study. Revista do Instituto de Medicina Tropical de São Paulo, 33: 459-464.

STEWIEN, K. E.; MEHNERT, D. U.; HÁRSI, C. M.; STEWIEN, E. T.; CANDEIAS, J. M. G. \& TANAKA K., 1994, Serotypes and electropherotypes of human rotavirus detected in the city of São Luís (MA), Brazil. Brazilian Journal of Medical and Biological Research, 27:1355-1361.

STEWIEN, K. E.; MOS, E. N.; YANAGUITA, R. M.; JEREZ, J. A.; DURIGON, E. L.; HÁRSI, C. M.; TANAKA, H.; MORAES, R. M.; SILVA, L. A.; SANTOS, M. A.; CANDEIAS, J. M. G.; TANAKA, K.; PERET, T. C. T.; BALDACCI, E. R. \& CLÍlIO, A. E., 1993. Viral, bacterial and parasitic pathogens associated with severe diarrhoea in the city of São Paulo, Brazil. Journal of Diarrhoeal Diseases Research, 11:148-152.

SUTM OLLER, F.; AZEREDO, R. S.; LACERDA, M. D.; BARTH, O. M.; PEREIRA, H. G.; HOFFER, E. \& SCHATZM AYR, H. G., 1982. An outbreak of gastroenteritis caused by both rotavirus and Shigella sonnei in a private school in Rio de Janeiro. Journal of Hygiene, 88:285-293.

TEIXEIRA, J. M.; CAM ARA, G. N. N. L.; PIMENTEL, P. F. V.; FERREIRA, M. N. R.; FERREIRA, M. S. R.; ALFIERI, A. A.; GENTSCH, J. R. \& LEITE, J. P. G., 1998. Human group $C$ rotavirus in children with diarrhea in the Federal District, Brazil. Brazilian Journal of Medical and Biological Research, 31: 1397-1403.
TEIXEIRA, J. M .; DE FIGUEIREDO, R. B.; DOS SAN TOS, H. M.; FERREIRA, M. N. \& CAM ARA, G. N. 1991. Aspectos epidemiológicos das infecções por rotavírus no Distrito Federal, Brasil. Revista da Sociedade Brasileira de Medicina Tropical, 24: 223-230.

TIMENETSKY, M. C.; SANTOS, N. \& GOUVEA, V., 1994 Survey of rotavirus $G$ and $P$ types associated with human gastroenteritis in São Paulo, Brazil from 1986 to 1992. Journal of Clinical Microbiology, 32: 2622-2624.

TIMENETSKY, M. C.; GOUVEA, V.; SANTOS, N.; ALGE, M. E.; KISIELLIUS, J. J.; CARMONA, R. C. C. \& THE STUDY GROUP ON DIARRHEA OF THE INSTITUTO ADOLFO LUTZ, 1996. Outbreak of severe gastroenteritis in adults and children associated with type $\mathrm{G} 2$ rotavirus. Journal of Diarrhoeal Diseases Research, 14:71-74.

TIMENETSKY, M. C. S. T.; GOUVEA, V.; SANTOS, N.; CARMONA, R. C. C. \& HOSHINO, Y., 1997. A novel human rotavirus serotype with dual G5-G11 specificity. Journal of General Virology, 78:1373-1378.

WHO (World Health Organization)/CDC (Centers for Disease Control and Prevention)/CVI (Children's Vaccine Initiative), 1997. Report. ConsensusWorkshop: Rotavi rus Vaccines for the Immunization of Children in Developing Countries. Geneva: WHO. 